\title{
In vitro comparison between inspiration synchronized and continuous vibrating mesh nebulizer during trans-nasal aerosol delivery
}

Jie $L i^{i^{*}}\left(\mathbb{D}\right.$, Wei Wu' ${ }^{2}$ and James B. Fink ${ }^{1,3}$

\footnotetext{
* Correspondence: Jie_Li@rush.edu 'Department of Cardiopulmonary Sciences, Division of Respiratory Care, Rush University Medical Center, 1620 W Harrison St, Tower LL1202, Chicago, IL 60612, USA Full list of author information is available at the end of the article
}

\begin{abstract}
Background: Compared to continuous vibrating mesh nebulizer (VMN), inspiration synchronized VMN has shown increased inhaled dose during noninvasive ventilation; however, its use during aerosol delivery via high-flow nasal cannula (HFNC) is still unknown.

Methods: An adult manikin was connected to a dual-chamber model lung, which was driven by a critical care ventilator to simulate spontaneous breathing. A HFNC system was utilized with temperature at $37^{\circ} \mathrm{C}$ while gas flow at 5, 10, 20, 40, and 60 $\mathrm{L} / \mathrm{min}$. Inspiration synchronized and continuous aerosol generation were compared at different positions (at the inlet of humidifier vs close to patient). One milliliter of albuterol $(2.5 \mathrm{mg} / \mathrm{mL})$ was used in each run $(n=3)$. Collection filter was placed at the trachea and was removed after each run. Drug was eluted from the filter and assayed with UV spectrophotometry ( $276 \mathrm{~nm})$.
\end{abstract}

Results: When nebulizer was placed close to patient, inhaled dose was higher with inspiration synchronized than continuous aerosol generation at all gas flows ( $p=$ 0.05 ) except at $5 \mathrm{~L} / \mathrm{min}$. When placed at the inlet of humidifier, compared to continuous, inspiration synchronized aerosol generated higher inhaled dose with gas flow set below 50\% of patient inspiratory flow $[23.9(20.6,28.3) \%$ vs $18.1(16.7,19.6) \%$, $p<0.001]$, but lower inhaled dose with gas flow set above $50 \%$ of patient inspiratory flow $[3.5(2.2,9.3) \%$ vs $9.9(8.2,16.4) \%, p=0.001]$. Regardless of breathing pattern, continuous aerosol delivered greater inhaled dose with nebulizer placed at humidifier than close to patient at all gas flows except at $5 \mathrm{~L} / \mathrm{min}$.

Conclusion: When the HFNC gas flow was set higher than $50 \%$ of patient inspiratory flow, no significant advantage was found in inspiration synchronized over continuous aerosol. However, inspiration synchronized aerosol generated 30\% more inhaled dose than continuous with gas flow set below $50 \%$ of patient inspiratory flow, regardless of nebulizer placement. Continuous nebulizer needs to be placed at the inlet of humidifier.

Keywords: High-flow nasal cannula, Inspiration synchronized nebulizer, Continuous aerosol, Vibrating mesh nebulizer 


\section{Background}

In recent years, aerosol delivery via high-flow nasal cannula (HFNC) has become a popular measure to deliver aerosol therapy [1-8], particularly for patients who are using HFNC concurrently [1-5]. At regular flow setting, trans-nasal albuterol delivery for stable patients with chronic obstructive airway diseases has been shown to elicit similar response as conventional nebulization treatment [6-8], such as small volume jet nebulizer via mask/mouthpiece or metered dose inhaler with spacer. Similarly, it has demonstrated better tolerance and comfort than jet nebulizer via mask for young pediatric patients [1-3].

Due to its features of no additional gas and little to no residual volume, vibrating mesh nebulizer (VMN) has been commonly utilized in trans-nasal aerosol delivery [1-5, 7-9]. However, the currently available commercial product of VMN generates aerosol continuously. This continuous production causes the waste of aerosolized medication during patient expiratory phase, which is up to three times longer than the inspiratory phase. Because of this drawback, VMN is commonly placed distal from the patient, making the circuit and humidifier chamber act as a reservoir to contain the aerosol generated during expiratory phase, resulting in more aerosol available to the patient [9]. The technique of synchronizing aerosol production with patient's inspiratory effort is available in small volume jet nebulizer, which shows threefold increase of inhaled aerosol mass over the conventional continuous jet nebulizer [10]. Michotte et al. integrated this algorithm into VMN and compared its efficiency with continuous VMN during noninvasive ventilation; both in vitro and in vivo studies found that inspiration synchronized VMN produced higher lung dosage than continuous VMN [11, 12]. However, little has been known about inspiration synchronized aerosol via HFNC. Thus, our objective of this study was to compare the inhaled dose of aerosol generated by inspiration synchronized vs continuous VMN via adult HFNC.

Gas flow setting during HFNC and patient's breathing pattern (quiet vs distressed breathing) have been identified as significant influential factors during trans-nasal aerosol delivery [13-18], as such, the two factors as well as nebulizer placement were also compared in our study.

\section{Methods}

\section{Experiment setup}

\section{Spontaneous breathing model}

An adult manikin (adult airway management trainer, Laerdal Medical AS, Stavanger, Norway) with anatomical airway was utilized in this experiment; a collection filter (Respirgard 303, CareFusion, San Diego, CA, USA) which was used to capture the inhaled aerosol was connected with the manikin's trachea and a dual-chamber model lung (TTL, Michigan Instruments, Grand Rapids, MI, USA). The two chambers could be moved together as for the connection via a rigid metal piece; one chamber was driven by a critical care ventilator (PB 840, Medtronic's, Minneapolis, $\mathrm{MN}$, USA), functioning as respiratory muscle to move the other chamber which was connected to the manikin to simulate spontaneous breathing. Nasal breathing was simulated by sealing the manikin's mouth (Fig. 1). Quiet breathing pattern was 


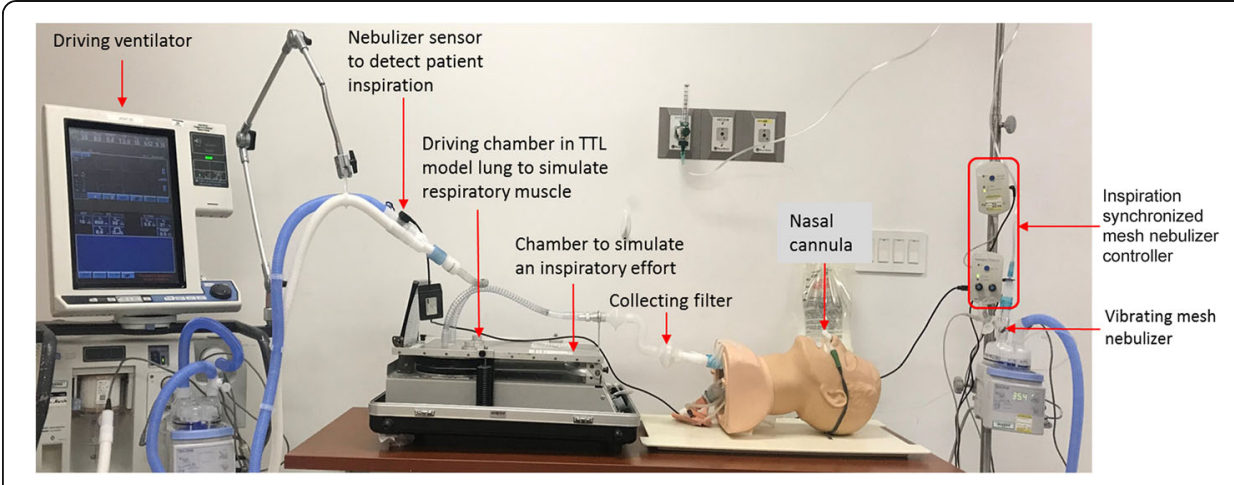

Fig. 1 Experiment setup

set as tidal volume (Vt) $500 \mathrm{~mL}$, respiratory rates (RR) 15 breaths per minute, inspiratory time $(\mathrm{Ti}) 1.33 \mathrm{~s}$, inspiratory to expiratory ratio (I:E) $1: 2$, and inspiratory flow $22.5 \mathrm{~L} / \mathrm{min}$, compared to distressed breathing set at Vt $700 \mathrm{~mL}$, RR 30 breaths per minute, Ti $1.0 \mathrm{~s}, \mathrm{I}: \mathrm{E}$ 1:1, and inspiratory flow $42 \mathrm{~L} / \mathrm{min}[13,15]$. These breathing patterns were achieved by adjusting ventilator settings, with the feedback from measurement by $\mathrm{NICO}_{2}$ monitor (Respironics, Murrysville, PA, USA), which was placed between the chamber and trachea.

\section{HFNC setup}

The Optiflow $^{\text {TM }}$ system (Fisher and Paykel, Auckland, New Zealand) was connected to an adult HFNC circuit with a heated humidifier (F\&P 850 system, Fisher and Paykel, Auckland, New Zealand); a large size of nasal cannula (Fisher and Paykel, Auckland, New Zealand) was connected with the circuit and placed on the manikin's nostrils. Humidifier temperature was set at $37^{\circ} \mathrm{C}$. A mass flowmeter (4040, TSI, Shoreview, MN, USA) was utilized to measure and guide accurate flow setting at 5, 10, 20, 40, and $60 \mathrm{~L} / \mathrm{min}$.

\section{VMN setup}

Inspiration synchronized VMN (Aerogen Solo, Aerogen Ltd., Galway, Ireland) was powered by a prototype control module, with a flow sensor placed at the inspiratory limb of the critical ventilator to detect the driving flow simulating spontaneous breathing. Nebulization was initiated when inspiratory flow was detected, and the duration of aerosol spray could be adjusted on the control module. In this study, aerosol spray duration was set at the first $50 \%$ of patient's inspiratory time, which meant aerosol was produced at the beginning $0.7 \mathrm{~s}$ of the $1.33 \mathrm{~s}$ Ti during quiet breathing and the beginning $0.5 \mathrm{~s}$ of the $1 \mathrm{~s}$ Ti during distressed breathing. Both inspiration synchronized and continuous VMN were compared at the placement of the inlet of humidifier vs close to patient (between the nasal cannula and circuit). Albuterol powder (1.0 g, SigmaAldrich, St. Louis, MO, USA) was reconstituted with $400 \mathrm{~mL}$ sterile water to prepare a concentration of $2.5 \mathrm{mg} / \mathrm{mL}, 1 \mathrm{~mL}$ of albuterol was used in each run, and 3 samples were repeated in each experiment. 


\section{Assay analysis}

After each nebulization, the filter was removed and eluted with $10 \mathrm{~mL}$ solution (20\% ethanol with $0.1 \mathrm{M} \mathrm{HCl}$ ), which was assayed with UV spectrophotometry $(276 \mathrm{~nm})$. After each run, the condensation in the circuit and nasal cannula was emptied and dried. Before initiating each experiment setting, the circuit was stabilized for a minimum of $1 \mathrm{~min}$.

\section{Statistical analysis}

Inhaled dose was calculated as a percentage of the amount of albuterol captured by the collecting filter to the nominal dose $(2.5 \mathrm{mg})$, and expressed as mean \pm SD for each experiment setting with different gas flow, breathing pattern, aerosol generation pattern, and nebulizer placement. Mann-Whitney test was used to compare the differences of the inhaled doses with those experiment settings. A $p$ value of $<0.05$ was considered to be statistically significant. Data analysis was conducted with SPSS statistical software (SPSS 26.0 for Windows; SPSS; Chicago, IL).

\section{Results}

Inhaled dose of inspiration synchronized vs continuous aerosol via VMN

For continuous aerosol, when nebulizer was placed close to patient, inhaled dose decreased as gas flow increased, regardless of breathing pattern; when nebulizer was placed at the inlet of humidifier, inhaled dose was similar at $5-20 \mathrm{~L} / \mathrm{min}$ then decreased at 40 and $60 \mathrm{~L} / \mathrm{min}$ with quiet breathing, while with distressed breathing, inhaled dose increased as gas flow increased from $5 \mathrm{~L} / \mathrm{min}$ then plateaued at 10 $40 \mathrm{~L} / \mathrm{min}$. Regardless of breath pattern, inhaled dose was higher with continuous VMN placed at the inlet of humidifier than placed close to patient at all gas flows except at $5 \mathrm{~L} / \mathrm{min}$ (Table 1 ).

For inspiration synchronized aerosol, inhaled dose peaked at $10 \mathrm{~L} / \mathrm{min}$ with quiet breathing, regardless of VMN placement; while during distressed breathing, inhaled dose peaked at $20 \mathrm{~L} / \mathrm{min}$ when nebulizer was placed at the inlet of humidifier, and peak inhaled dose was maintained at 10 and $20 \mathrm{~L} / \mathrm{min}$ when nebulizer was placed close to the patient (Fig. 2).

With nebulizer placed at the inlet of humidifier, continuous aerosol generated higher inhaled dose than inspiration synchronized when gas flow was $\geq 20 \mathrm{~L} / \mathrm{min}$ in quiet breathing $[8.2(6.3,16.1) \%$ vs $3.5(1.2,9.5) \%, p=0.03]$ and when gas flow was $\geq 40 \mathrm{~L} / \mathrm{min}$ in distressed breathing $(13.2 \pm 3.7 \%$ vs $5.7 \pm 3.7 \%, p=0.006)$; however, inspiration synchronized aerosol generated higher inhaled dose than continuous when gas flow was at $10 \mathrm{~L} / \mathrm{min}$ with quiet breathing $(27.6 \pm 1.2 \%$ vs $19.8 \pm$ $0.8 \%, p=0.05)$ and when gas flow was $\leq 20 \mathrm{~L} / \mathrm{min}$ with distressed breathing (25.3 $\pm 4.7 \%$ vs $16.1 \pm 2.6 \%, p<0.001)$.

With nebulizer placed close to patient, inhaled dose was higher with inspiration synchronized aerosol than with continuous in both quiet and distressed breathing at each gas flow $(p=0.05)$, except when gas flow was $5 \mathrm{~L} /$ $\min (p=0.33)$. 
Table 1 Comparison between inspiration synchronized and continuous nebulizer at different placement with quiet vs distressed breathing

\begin{tabular}{|c|c|c|c|c|}
\hline \multirow{2}{*}{$\begin{array}{l}\text { Nebulizer } \\
\text { position }\end{array}$} & \multirow[t]{2}{*}{ Breathing pattern } & \multirow{2}{*}{$\begin{array}{l}\text { HFNC } \\
\text { gas } \\
\text { flow } \\
\text { rate } \\
\text { (L/ } \\
\text { min) }\end{array}$} & \multicolumn{2}{|c|}{ Inhaled dose (\%) } \\
\hline & & & $\begin{array}{l}\text { Inspiration } \\
\text { synchronized } \\
\text { nebulizer }\end{array}$ & $\begin{array}{l}\text { Continuous } \\
\text { nebulizer }\end{array}$ \\
\hline \multirow[t]{10}{*}{ Inlet of humidifier } & \multirow[t]{5}{*}{ Quiet (500 mL/15 bpm/1:2/22.5 L/min) } & 5 & $19.8 \pm .8$ & $19.5 \pm .3$ \\
\hline & & 10 & $27.6 \pm 1.2$ & $19.8 \pm .8$ \\
\hline & & 20 & $9.6 \pm .3$ & $16.5 \pm .8$ \\
\hline & & 40 & $3.5 \pm .1$ & $8.8 \pm 1.0$ \\
\hline & & 60 & $1.1 \pm .04$ & $6.3 \pm .2$ \\
\hline & \multirow[t]{5}{*}{ Distressed (700 mL/30 bpm/1:1/42 L/min) } & 5 & $21.0 \pm .6$ & $12.9 \pm 1.6$ \\
\hline & & 10 & $23.9 \pm 1.3$ & $17.5 \pm 1.0$ \\
\hline & & 20 & $31.2 \pm 1.3$ & $17.8 \pm .2$ \\
\hline & & 40 & $9.1 \pm .2$ & $16.5 \pm .3$ \\
\hline & & 60 & $2.3 \pm .2$ & $9.8 \pm .7$ \\
\hline \multirow[t]{10}{*}{ Close to patient } & \multirow[t]{5}{*}{ Quiet (500 mL/15 bpm/1:2/22.5 L/min) } & 5 & $13.4 \pm .3$ & $24.1 \pm .8$ \\
\hline & & 10 & $24.1 \pm 1.0$ & $15.8 \pm .6$ \\
\hline & & 20 & $18.0 \pm 1.8$ & $10.0 \pm .4$ \\
\hline & & 40 & $7.8 \pm .6$ & $3.9 \pm .3$ \\
\hline & & 60 & $4.7 \pm .4$ & $2.0 \pm .1$ \\
\hline & \multirow[t]{5}{*}{ Distressed (700 mL/30 bpm/1:1/42 L/min) } & 5 & $12.5 \pm 1.4$ & $19.0 \pm 1.0$ \\
\hline & & 10 & $24.2 \pm .9$ & $17.8 \pm .5$ \\
\hline & & 20 & $23.7 \pm .7$ & $13.6 \pm .2$ \\
\hline & & 40 & $12.0 \pm .3$ & $8.3 \pm .6$ \\
\hline & & 60 & $6.9 \pm .1$ & $3.8 \pm .1$ \\
\hline
\end{tabular}

Inhaled dose of inspiration synchronized vs continuous aerosol with the gas flow to patient inspiratory flow ratio

Using the ratio of administered gas flow to patient inspiratory flow (GF:IF) as $X$-axis and inhaled dose (\%) as $Y$-axis to draw a scatterplot with inspiration synchronized and continuous VMN placed at different positions (Fig. 3), inhaled dose increased as the

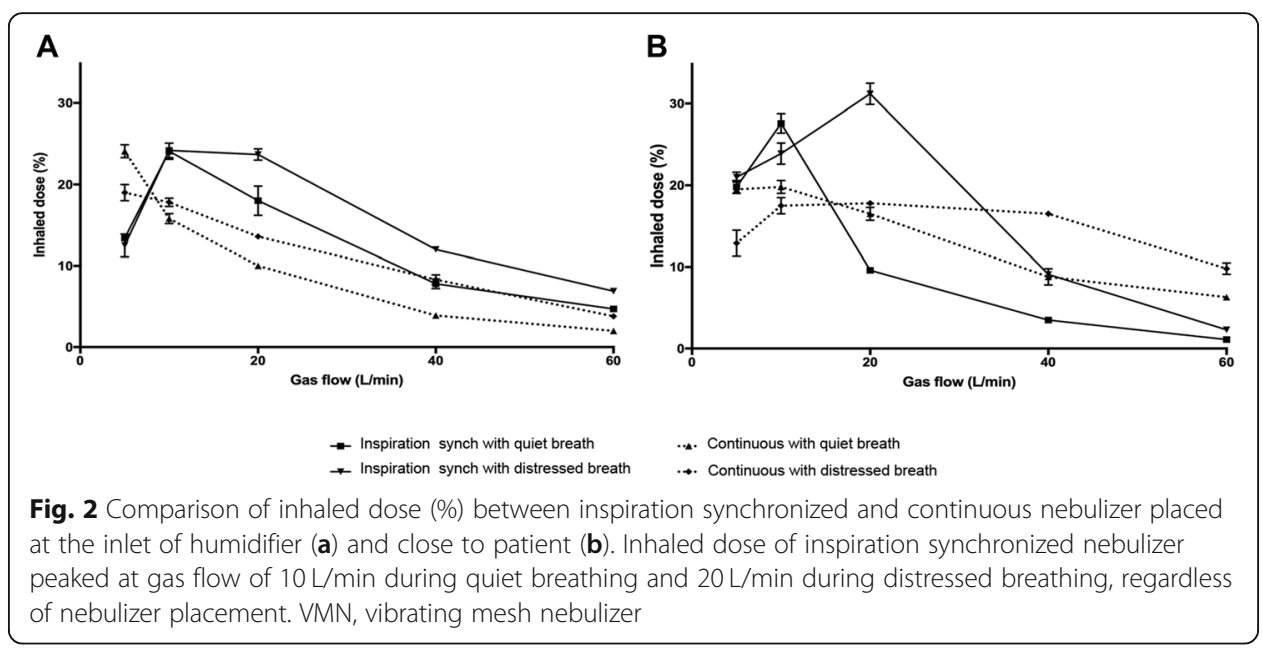




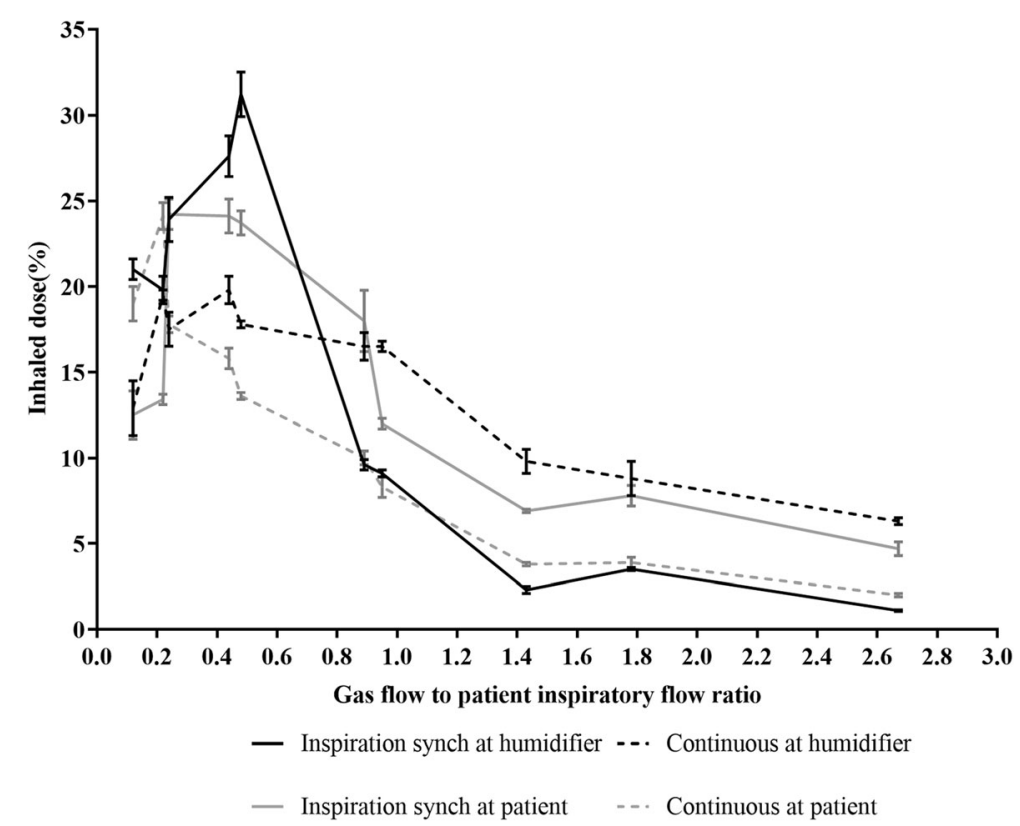

Fig. 3 The relationship between inhaled dose and the gas flow to patient inspiratory flow ratio with inspiration synchronized and continuous aerosol

GF:IF ratio increased, and peaked around the GF:IF ratio of 0.5 , except continuous VMN placed close to patient that peaked at GF:IF $=0.22$.

Thus, using GF:IF $=0.5$ as a delineator, inhaled dose with GF:IF $<0.5$ was higher than that with GF:IF $>0.5$ in both inspiration synchronized and continuous aerosol $(p<0.001)$ at both nebulizer placements $(p<0.001)$ (Table 2$)$. When GF:IF was $>0.5$, compared to continuous nebulizer, inspiration synchronized nebulizer generated lower inhaled dose $[3.5(2.2,9.3) \%$ vs $9.9(8.2,16.4) \%, p=$ 0.001] with nebulizer placed at the inlet of humidifier, but it generated higher inhaled dose $[8.0(6.8,12.4) \%$ vs $4.0(3.6,9.0) \%, p=0.010]$ with nebulizer placed close to patient, and this inhaled dose was similar to continuous nebulizer placed at the inlet of humidifier $[8.0(6.8,12.4) \%$ vs $9.9(8.2,16.4) \%, p=0.31]$. However, when GF:IF was $<0.5$, inspiration synchronized aerosol generated higher inhaled dose than continuous with nebulizer placed at the inlet of humidifier [23.9 (20.6, $28.3) \%$ vs $18.1(16.7,19.6) \%, p<0.001]$ and similar inhaled dose with nebulizer placed close to patient $(p=0.604)$.

\section{Discussion}

To our knowledge, this study for the first time compared the inhaled dose of inspiration synchronized with continuous aerosol generated with VMN at different placements, gas flows, and breathing patterns. When VMN was placed close to patient, inspiration synchronized aerosol generated higher inhaled dose than continuous at all gas flows except at $5 \mathrm{~L} / \mathrm{min}$. However, when nebulizer was placed at the inlet of humidifier, compared to continuous, inspiration synchronized aerosol generated lower inhaled dose with GF:IF > 0.5 while it generated higher inhaled dose with GF:IF $<0.5$. 
Table 2 Comparison of inspiration synchronized vs continuous nebulizer with different GF:IF and nebulizer placements

\begin{tabular}{lllll}
\hline Nebulizer placement & Nebulizer type & Inhaled dose $(\%)$ & & \\
\cline { 3 - 4 } & & $\mathrm{GF}: \mathrm{IF}>0.5(n=60)$ & $\mathrm{GF}: \mathrm{IF}<0.5(n=60)$ & \\
\hline Inlet of humidifier & Continuous & $9.9(8.2,16.4)$ & $18.1(16.7,19.6)$ & $<0.001$ \\
& Inspiration synchronized & $3.5(2.2,9.3)$ & $23.9(20.6,28.3)$ & $<0.001$ \\
& $p$ & 0.001 & $<0.001$ & $<0.001$ \\
Close to patient & Continuous & $4.0(3.6,9.0)$ & $17.6(15.2,20.1)$ & $<0.001$ \\
& Inspiration synchronized & $8.0(6.8,12.4)$ & $23.1(13.4,24.1)$ & \\
& $p$ & 0.010 & 0.604 & \\
$\begin{array}{l}\text { Comparison of inspiration synchronized nebulizer placed } \\
\text { at inlet of humidifier vs close to patient }\end{array}$ & 0.015 & 0.067 & \\
$\begin{array}{l}\text { Comparison of inspiration synchronized and continuous } \\
\text { nebulizer at its best position }\end{array}$ & 0.31 & & \\
\hline
\end{tabular}

GF gas flow, IF patient inspiratory flow

\section{Comparison of inspiration synchronized vs continuous VMN placed at different position}

When continuous nebulizer is placed close to patient, little to no aerosol could be stored considering the small volume of nasal cannula; thus, aerosol is largely wasted during exhalation. Inspiration synchronized aerosol generates higher inhaled dose by reducing the waste during exhalation; this explains our findings with nebulizer placed close to patient, which agreed with the finding that higher inhaled dose with breath actuated jet nebulizer than continuous jet nebulizer when it was placed at the Y-piece during invasive ventilation [10]. Moreover, Michotte et al. found higher inhaled dose with inspiration synchronized VMN than continuous VMN during noninvasive ventilation, particularly when nebulizer was placed between the single-limb ventilator and exhalation port; the waste of aerosol was more significant with continuous VMN than inspiration synchronized VMN [11]. In Golshahi et al.'s study, they used similar breathing parameters during quiet breathing (Vt $500 \mathrm{ml}$, RR 15) but only investigated one gas flow $(20 \mathrm{~L} / \mathrm{min})$, with nebulizer placed close to patient; they also found higher inhaled dose at nostril level with inspiration synchronized than continuous aerosol [19]. However, we found one exception that with gas flow at $5 \mathrm{~L} / \mathrm{min}$, inhaled dose was higher with continuous than inspiration synchronized aerosol, which might be explained by the significant reduction of the washing out effects due to the extremely low flow, resulting in reservoir of aerosol during exhalation for continuous aerosol. In contrast, because of the low flow rate to carry aerosol, aerosol generated at the inspiratory phase might not be able to fully reach the trachea yet before exhalation [20, 21].

Due to the concerns of the aerosol waste during exhalation, continuous VMN was found to generate higher inhaled dose when placed at the inlet of humidifier, using the circuit and humidifier chamber as reservoir during exhalation. However, the reservoir advantages were predominantly with high gas flow, specifically with GF:IF > 0.5. This finding agreed with the results in our previous pediatric study [14]. With GF:IF $<0.5$, the reservoir benefits were attenuated; this might be explained by the gravitational sedimentation effects, which increased as the aerosol stayed longer in the circuit and chamber due to the low flow $[21,22]$. The optimal period that the aerosol stays in the circuit and chamber to generate the best inhaled dose needs to balance the reservoir benefits and the gravitational sedimentation effects, depending on the reservoir volume and the 
speed of the transporting gas [21, 22]. As the reservoir volume of adult HFNC system is a constant $(\sim 1000 \mathrm{~mL}$ in adult circuit), this optimal point depends on the transporting gas, including the HFNC gas flow and patient inspiratory flow. From our previous adult in vitro study [13] and this study, using the same adult HFNC system, we found the highest inhaled dose was generated when the GF:IF was around 0.5. The rationale of this number needs more mathematical efforts to explore in the future, but this phenomenon was also seen in both in vitro and in vivo studies with neonatal invasive ventilation that with appropriate reservoir volume and transporting gas flow, continuous VMN even the expiratory actuated VMN could generate higher inhaled dose than inspiratory actuated VMN with inappropriate reservoir volume or transporting gas flow [23, 24]. Similarly, Berlinski et al. speculated that there was an optimal bias flow setting to carry aerosol with continuous VMN placed at the inlet of humidifier during invasive ventilation [21].

In contrast, when inspiration synchronized VMN is placed at the inlet of humidifier, aerosol generated in the inhalation phase might be largely wasted, as patient might already start exhalation when the gas carries aerosol to patient. This asynchrony might be more prominent with high gas flow, which explains our finding that continuous aerosol generated higher inhaled dose than inspiration synchronized aerosol when the VMN was placed at the inlet of humidifier and with high gas flow. However, when gas flow was reduced to $<50 \%$ of patient inspiratory flow, this waste was significantly reduced. Instead, aerosol starts to be stored in the system as a bolus before the next inhalation; patient inhales the bolus of aerosol during the next inhalation [22]. Similar to continuous VMN, longer stay with lower transporting flow may cause more gravitational sedimentation; thus, the optimal stay period depends on the HFNC gas flow and patient inspiratory flow, which was found to be approximately 0.5 .

In all, when GF:IF was > 0.5, placing inspiration synchronized VMN close to patient generated higher inhaled dose than that at the inlet of humidifier $(p=0.010)$; this inhaled dose was comparable to that with continuous VMN at its best position (inlet of humidifier) $(p=0.31)$. When GF:IF was $<0.5$, regardless of the placement, inhaled dose with inspiration synchronized VMN was $30 \%$ higher than that with continuous VMN.

\section{Clinical implication}

Compared to the current commercially available continuous VMN, the inspiration synchronized VMN did not generate clinically relevant increment of inhaled dose, particularly at high gas flows. However, this finding was not surprising, as the inhaled dose was only slightly higher with inspiration synchronized VMN than continuous VMN in the previous in vitro and in vivo adult studies during noninvasive ventilation [11, 12], while the inhaled dose was found to be even lower with inspiration synchronized VMN than continuous VMN during neonatal invasive ventilation in both in vitro and in vivo studies [23, 24]. Additionally, all these studies found the delivery time with inspiration synchronized VMN was two- to threefold longer than continuous VMN [11, 12, 23, 24]. As such, the authors argued if it was worthwhile to use inspiration synchronized VMN [11, 12, 23, 24].

Nevertheless, our findings can enhance the understanding of trans-nasal aerosol delivery, which has similarities as well as differences with noninvasive ventilation and 
invasive ventilation. Particularly, the impact of reservoir benefits vs gravitational sedimentation effects on the trans-nasal aerosol delivery, such as the optimal GF:IF ratio, is worthy to investigate, in order to improve trans-nasal aerosol delivery. Even though no commercially available device allows us to measure patient inspiratory flow breath by breath, the concept of the optimal flow ratio can still guide clinicians to titrate gas flow during aerosol delivery via HFNC, rather than using one constant flow. More importantly, once devices to monitor patient inspiratory flow are commercially available, using inspiration synchronized VMN at the inlet of humidifier at the optimal gas flow can significantly increase inhaled dose by $50-75 \%$. Additionally, regarding the optimal placement of continuous VMN in adult populations, our findings support the current clinical practice to place continuous VMN at the inlet of humidifier rather than close to patient, especially at high gas flow settings.

\section{Limitations}

In this study, we only investigated limited sets of breathing parameters and HFNC gas flows, and only 10 GF:IF ratios were investigated; even the optimal GF:IF (around 0.5) agreed with our previous study [13], it still requires more settings specifically with different GF:IF ratios to confirm. Moreover, we only used one manikin with one size of anatomical airway; even it was made based on the most common size of healthy male adults, our results still could not represent all patients. Future studies with more sizes of anatomical airways particularly with different airway diseases are needed. Additionally, we only investigated the aerosol spray duration at the beginning $50 \%$ of inspiratory phase; more studies might be needed to explore different aerosol spray durations to seek for the optimal percentage. Lastly, similar to all the in vitro studies [11, 13-16, 19-22, 24], the manikin's airway did not have physiological functions such as heat and humidify the gas, filter and absorb the medication by the upper airway, etc; additionally, the filter can capture all the aerosol while some aerosol might be exhaled in vivo, contributing to the higher aerosol deposition in the lung with in vitro study.

\section{Conclusion}

Continuous nebulizer placed at the inlet of humidifier delivered greater inhaled dose than placement at the patient. When HFNC gas flow was higher than $50 \%$ of patient inspiratory flow, inspiration synchronized aerosol did not add clinical advantage over continuous nebulizer placed at the inlet of humidifier. However, when the HFNC gas flow was set lower than $50 \%$ of patient inspiratory flow, inspiration synchronized nebulizer placed at the inlet of humidifier generated higher inhaled dose than continuous nebulizer, regardless of nebulizer position. Further research is required to understand variables and potential clinical benefits.

Abbreviations

GF:IF: Gas flow to patient inspiratory flow; HFNC: High-flow nasal cannula; I:E: Inspiratory to expiratory ratio; RR: Respiratory rates; Ti: Inspiratory time; VMN: Vibrating mesh nebulizer; Vt: Tidal volume 


\section{Authors' contributions}

$J$ conceived and designed the study, conducted the study, analyzed and interpreted the data, and drafted and revised the manuscript. WW conducted the study, collected the data, and revised the manuscript. JBF conceived and supervised the study and revised the manuscript. All authors read and approved the final manuscript.

\section{Funding}

This research received no external funding.

\section{Availability of data and materials}

The datasets used and/ or analyzed during the current study are available from the corresponding author on reasonable request.

\section{Ethics approval and consent to participate}

Not applicable.

\section{Consent for publication}

Not applicable.

\section{Competing interests}

JBF is the Chief Science Officer for Aerogen Pharma Corp and discloses relationships with Dance Biopharm. The companies had no role in the design of the study; in the collection, analyses, or interpretation of data; in the writing of the manuscript; or in the decision to publish the results. All other authors declare that they have no competing interests.

\section{Author details}

${ }^{1}$ Department of Cardiopulmonary Sciences, Division of Respiratory Care, Rush University Medical Center, 1620 W Harrison St, Tower LL1202, Chicago, IL 60612, USA. ²Department of Critical Care Medicine, Shanghai Zhongshan Hospital, Fu Dan University, Shanghai, China. ${ }^{3}$ Aerogen Pharma Corp, San Mateo, CA, USA.

Received: 18 October 2019 Accepted: 14 January 2020

Published online: 31 January 2020

\section{References}

1. Morgan SE, Mosakowski S, Solano P, Hall JB, Tung A (2015) High-flow nasal cannula and aerosolized beta agonists for rescue therapy in children with bronchiolitis: a case series. Respir Care 60(9):e161-e165

2. Baudin F, Buisson A, Vanel B, Massenavette B, Pouyau R, Javouhey E (2017) Nasal high flow in management of children with status asthmaticus: a retrospective observational study. Ann Intensive Care 7(1):55

3. Valencia-Ramos J, Miras A, Cilla A, Ochoa C, Arnaez J (2018) Incorporating a nebulizer system into high-flow nasal cannula improves comfort in infants with bronchiolitis. Respir Care 63(7):886-893

4. Ammar MA, Sasidhar M, Lam SW (2018) Inhaled epoprostenol through noninvasive routes of ventilator support systems. Ann Pharmacother 52(12):1173-1181

5. Li J, Harnois LJ, Markos B, Roberts KM, Homoud SA, Liu J, Mirza S, Vines D (2019) Epoprostenol delivered via high flow nasal cannula for ICU subjects with severe hypoxemia comorbid with pulmonary hypertension or right heart dysfunction. Pharmaceutics 11(6):281

6. Braunlich J, Wirtz H (2018) Oral versus nasal high-flow bronchodilator inhalation in chronic obstructive pulmonary disease. J Aerosol Med Pulm Drug Deliv 31(4):248-254

7. Reminiac F, Vecellio L, Bodet-Contentin L, Gissot V, Le Pennec D, Salmon Gandonniere C, Cabrera M, Dequin PF Plantier L, Ehrmann S (2018) Nasal high-flow bronchodilator nebulization: a randomized cross-over study. Ann Intensive Care 8(1):128

8. Li J, Zhao M, Hadeer M, Luo J, Fink JB (2019) Dose response to transnasal pulmonary administration of bronchodilator aerosols via nasal high-flow therapy in adults with stable chronic obstructive pulmonary disease and asthma. Respiration 98(5):401-409

9. Dugernier J, Reychler G, Vecellio L, Ehrmann S (2019) Nasal high-flow nebulization for lung drug delivery: theoretical experimental, and clinical application. J Aerosol Med Pulm Drug Deliv. https://doi.org/10.1089/jamp.2019.1524 [Epub ahead of print]

10. Miller DD, Amin MM, Palmer LB, Shah AR, Smaldone GC (2003) Aerosol delivery and modern mechanical ventilation: in vitro/in vivo evaluation. Am J Respir Crit Care Med 168(10):1205-1209

11. Michotte JB, Staderini E, Le Pennec D, Dugernier J, Rusu R, Roeseler J, Vecellio L, Liistro G, Reychler G (2016) In vitro comparison of a vibrating mesh nebulizer operating in inspiratory synchronized and continuous nebulization modes during noninvasive ventilation. J Aerosol Med Pulm Drug Deliv 29(4):328-336

12. Michotte JB, Staderini E, Aubriot AS, Jossen E, Dugernier J, Liistro G, Reychler G (2018) Pulmonary drug delivery following continuous vibrating mesh nebulization and inspiratory synchronized vibrating mesh nebulization during noninvasive ventilation in healthy volunteers. J Aerosol Med Pulm Drug Deliv 31(1):33-41

13. Li J, Gong L, Fink JB (2019) The ratio of nasal cannula gas flow to patient inspiratory flow on trans-nasal pulmonary aerosol delivery for adults: an in vitro study. Pharmaceutics 11(5):225

14. Li J, Gong L, Ari A, Fink JB (2019) Decrease the flow setting to improve trans-nasal pulmonary aerosol delivery via "highflow nasal cannula" to infants and toddlers. Pediatr Pulmonol 54(6):914-921

15. Reminiac F, Vecellio L, Heuze-Vourc'h N, Petitcollin A, Respaud R, Cabrera M, Pennec DL, Diot P, Ehrmann S (2016) Aerosol therapy in adults receiving high flow nasal cannula oxygen therapy. J Aerosol Med Pulm Drug Deliv 29(2):134-141 
16. Bennett G, Joyce M, Sweeney L, MacLoughlin R (2019) In vitro study of the effect of breathing pattern on aerosol delivery during high-flow nasal therapy. Pulmonary Therapy 5(1):43-54

17. Corcoran TE, Saville A, Adams PS, Johnston DJ, Czachowski MR, Domnina YA, Lin JH, Weiner DJ, Huber AS, Sanchez De Toledo J, Lo CW (2019) Deposition studies of aerosol delivery by nasal cannula to infants. Pediatr Pulmonol 54(8):1319-1325

18. Alcoforado L, Ari A, Barcelar JM, Brandao SCS, Fink JB, Andrade AD (2019) Impact of gas flow and humidity on transnasal aerosol deposition via nasal cannula in adults: a randomized cross-over study. Pharmaceutics 11(7):320

19. Golshahi L, Longest PW, Azimi M, Syed A, Hindle M (2014) Intermittent aerosol delivery to the lungs during high-flow nasal cannula therapy. Respir Care 59(10):1476-1486

20. Berlinski A, Willis JR (2013) Albuterol delivery by 4 different nebulizers placed in 4 different positions in a pediatric ventilator in vitro model. Respir Care 58(7):1124-1133

21. Berlinski A, Willis JR (2015) Effect of tidal volume and nebulizer type and position on albuterol delivery in a pediatric model of mechanical ventilation. Respir Care 60(10):1424-1430

22. Ari A, Atalay OT, Harwood R, Sheard MM, Aljamhan EA, Fink JB (2010) Influence of nebulizer type, position, and bias flow on aerosol drug delivery in simulated pediatric and adult lung models during mechanical ventilation. Respir Care 55(7):845-851

23. Dubus JC, Vecellio L, De Monte M, Fink JB, Grimbert D, Montharu J, Valat C, Behan N, Diot P (2005) Aerosol deposition in neonatal ventilation. Pediatr Res 58(1):10-14

24. Sidler-Moix AL, Dolci U, Berger-Gryllaki M, Pannatier A, Cotting J, Di Paolo ER (2013) Albuterol delivery in an in vitro pediatric ventilator lung model: comparison of jet, ultrasonic, and mesh nebulizers. Pediatr Crit Care Med 14(2):e98-102

\section{Publisher's Note}

Springer Nature remains neutral with regard to jurisdictional claims in published maps and institutional affiliations.

\section{Submit your manuscript to a SpringerOpen ${ }^{\circ}$ journal and benefit from:}

- Convenient online submission

- Rigorous peer review

- Open access: articles freely available online

- High visibility within the field

Retaining the copyright to your article

Submit your next manuscript at $\boldsymbol{\sim}$ springeropen.com 